\title{
Efficient Transdermal Delivery of Benfotiamine in an Animal Model
}

\author{
Gyula Varadi $\stackrel{ }{ }$, Zhen Zhu and Stephen G. Carter \\ BioChemics, Inc., 99 Rosewood Drive, Suite 270, Danvers, MA 01923-4537, USA \\ ${ }^{\square}$ Corresponding Author: Gyula Varadi, E-mail: gvaradi@biochemics.com; Tel.: +1-978-750-0090; Fax: +1-978-750- \\ 0080
}

Received: November 13, 2014; Revised: December 13, 2014; Published: January 09, 2015

\begin{abstract}
We designed a transdermal system to serve as a delivery platform for benfotiamine utilizing the attributes of passive penetration enhancing molecules to penetrate through the outer layers of skin combined with the advance of incorporating various peripherally-acting vasodilators to enhance drug uptake. Benfotiamine, incorporated into this transdermal formulation, was applied to skin in an animal model in order to determine the ability to deliver this thiamine pro-drug effectively to the sub-epithelial layers. In this proof of concept study in guinea pigs, we found that a single topical application of either a solubilized form of benfotiamine (15 mg) or a microcrystalline suspension form $(25 \mathrm{mg})$ resulted in considerable increases of the dephosphorylated benfotiamine (S-benzoylthiamine) in the skin tissue as well as in significant increases in the thiamine and thiamine phosphate pools compared to control animals. The presence of $a \sim 8000 x$ increase in thiamine and increases in its phosphorylated derivatives in the epidermis and dermis tissue of the test animals gives a strong indication that the topical treatment with benfotiamine works very well for the desired outcome of producing an intracellular increase of the activating cofactor pool for transketolase enzyme, which is implicated in the pathophysiology of diabetic neuropathy.
\end{abstract}

\section{Keywords}

Transdermal drug delivery; benfotiamine; solubilized benfotiamine; microcrystalline benfotiamine cream; thiamine, pentose phosphate cycle, pharmacokinetics; diabetic peripheral neuropathy

\section{Introduction}

In diabetic conditions, hyperglycemia induces an altered cellular metabolism, and through a series of events results in the creation of damaging cellular metabolites by influencing a number of glucose metabolizing pathways $[1,2]$. Elevated glucose level increases the metabolism through the polyol pathway; increases fructose-6-phosphate and glyceraldehyde-3-phosphate levels, which latter in turn increases the use of the diacylglycerol pathway leading to an increase in protein kinase $C$ pathway; increases the production of superoxide molecules and results in increased production of Advanced Glycation Endproducts (AGEs) [2], a biochemical problem known to be affected in neuropathy. AGEs inhibit key cellular proteins from functioning properly [2-4]. In addition, AGEs have been implicated in the induction of 
apoptosis, including peripheral nerve cells resulting eventually in the loss of sensation to the affected area and in an altered neuronal signaling process, which may present as pain $[1,2,5]$.

There are many candidate molecular targets for the treatment of diabetic neuropathy [6-8]. Several have been addressed through clinical trial evaluations [8] and most have failed [9]. One of the most considered endpoints for the development of a therapeutic for this diabetic complication is the treatment of pain associated with the neuronal deterioration. As a result, there have been several candidate therapies using oral and topically applied pain relievers ranging from pregabalin $[10,11]$ to capsaicin [12].

Apparently, in both forms (type 1 and type 2) of diabetic condition there is about $70 \%$ thiamine deficiency as measured in the plasma of diabetic patients [13-15] but the physiological mechanism associated with this deficiency has not been clarified yet. However, a number of studies found an altered thiamine handling in the kidneys of diabetic patients [16-18]. Benfotiamine, (S-benzoylthiamine-Omonophosphate), a derivative of the vitamin B1 or thiamine, has a much higher bioavailability than thiamine and, as a result, accumulates in the target tissues much more than thiamine itself $[15,19,20]$. Thiamine absorption from oral benfotiamine is approximately five times greater than from conventional thiamine supplements [21-23].

Once benfotiamine has been transported to the target tissue, it is converted through a series of metabolic and enzymatic steps to S-benzoylthiamine, which after internalization into the cell forms thiamine. This latter then serves as a substrate for enzymatic conversion to form thiamine mono-, di-, and triphosphates. It is however the thiamine diphosphate (TDP) that is responsible for binding to and activating the enzyme transketolase, a critical enzyme for the metabolism of the hyperglycemic by-products via the pentose phosphate pathway to generate metabolic products that are not damaging to the cells.

Benfotiamine was employed to treat alcoholic neuropathy $[24,25]$ sciatica and other painful nerve conditions [26,27] known to be affected with low thiamine content [28-30]. The application of benfotiamine and the resulting activation of the enzyme transketolase in the diabetic, hyperglycemic system can also produce beneficial effects on general nerve health. Benfotiamine has been shown in many preclinical [21,31-43] as well as clinical studies [44-57] to prevent the formation of AGEs [21,53] and eventually with continued treatment to reverse the symptoms associated with the neuropathy $[46,47,52,57]$. By increasing intracellular levels of thiamine, benfotiamine indirectly induces enzymatic and biochemical pathways [58-60] through elevated concentrations of thiamine diphosphate resulting in a reduced level of damaging glucose-derived chemical protein species [21,22,32,37-39,60-62].

Benfotiamine is currently offered as a prescriptive drug for the treatment of diabetic neuropathy in Europe in an oral form. It is also available for similar indications as a homeopathic medicine and as a dietary supplement. The typical oral dose recommended is $40-450 \mathrm{mg} /$ day $[63,64]$. The topical application of benfotiamine may allow more prodrug to be introduced into the target tissues and, as a result, potentially generate a greater therapeutic effect.

\section{Experimental}

We prepared two topical formulations for these studies. The topical formulation termed as $3 \%$ benfotiamine was prepared according to a VALE formulation [65] and contained $3 \%$ benfotiamine in soluble form, neutralized with arginine. The $5 \%$ topical formulation contained $5 \%$ benfotiamine, also in a VALE formulation, but in microcrystalline form. The stability of these products was tested after one year storage at $4{ }^{\circ} \mathrm{C}$ and we found that $89 \%$ of benfotiamine was present in the active chemical form. 
We utilized male Hartley guinea pigs (ca. 250-300 g) for pharmacokinetic studies with two topical benfotiamine formulations. The guinea pigs fur was clipped from their back, and an area of $4 \times 4 \mathrm{~cm}$ depilated with Nair. After ca. 24 hours, $0.5 \mathrm{~g}$ of test formulation was applied to a $2 \times 4 \mathrm{~cm}$ area. The test formulations tested either contained a solubilized topical benfotiamine (3\%) yielding a dose of $15 \mathrm{mg}$ of benfotiamine or a microcrystalline suspension form of benfotiamine (5\%) yielding a dose of $25 \mathrm{mg}$ benfotiamine.

At $0.5,1,2,4,8$ and 24 hours after application, groups of 5 animals were anesthetized with isoflurane and blood removed by cardiac stick. One group of 5 untreated animals was anesthetized and blood removed as vehicle control. Blood samples were directly processed to analyze benfotiamine, S-benzoylthiamine, thiamine and its derivatives by HPLC [66-70].

The skin below the area of topical application on each animal in the 24 hour exposure group was cleaned, rubbed with alcohol, with the intent to remove the stratum corneum, excised, weighed, homogenized in phosphate buffered saline, centrifuged, and ca. $2 \mathrm{ml}$ extract processed for pharmacokinetic analyses [66-70].

The blood and the homogenized skin tissue were evaluated at various time points following the single topical application for the presence of the formulated active pharmacological ingredient (BC-DN-01: Benfotiamine); the dephosphorylated drug intermediate (SBT: S-benzoylthiamine); as well as the cellular metabolites of thiamine (T); thiamine diphosphate; (TDP) and thiamine monophosphate (TMP).

\section{Results and Discussion}

The biochemistry and required chemical conversions for benfotiamine from a phosphorylated openringed structure to a de-phosphorylated closed ring and then subsequently forming thiamine and the phosphorylated species of thiamine to serve as cofactors in the transketolase reactions are found in many cell types including the skin tissue epidermal and dermal cells, as well as presumably peripheral nerve endings in the skin $[22,23,59-62]$. We believe that the delivery of benfotiamine to a patient via a topical route, as opposed to an oral administration, offers significantly greater efficacy as a result of the greater quantity of the drug directly deposited into the skin tissue where the neuronal endings are located.

To examine this concept, we initiated a set of experiments to first demonstrate the viability and stability of preparing a topical formulation of benfotiamine. While the substance benfotiamine has been available for use as a solid and orally delivered therapeutic for several years the development of a novel topical formulation of benfotiamine has been completed for these studies. We formulated benfotiamine into topical preparation to maximize local drug accumulation and to minimize systemic distribution [65]. The goal of these formulations and administration route was to deliver significantly greater quantities of the drug to the afflicted peripheral dermal neuronal tissue.

Next, we have performed a series of animal pharmacokinetic and tissue deposition experiments to determine the time course of appearance of thiamine derivatives in the plasma after treatment with benfotiamine formulations. In addition, we also analyzed the amounts of thiamine and the phosphorylated cellular metabolites in the skin tissue at a $24 \mathrm{~h}$ time point after topical treatment with benfotiamine.

We measured the thiamine (T), thiamine diphosphate (TDP), thiamine monophosphate (TMP) and calculated the level of total thiamine derivatives (Total) in the blood after the application of $0.5 \mathrm{~g}$ of $3 \%$ solubilized benfotiamine topical formulation. Upon treatment, we observed a sharp rise in the blood concentration of each of the thiamine derivatives within 30 minutes of the drug application (Figure 1). There was an additional increase until one hour, followed by a modest decline until two hours, then the 
blood concentration of the individual derivatives and the total remained at an elevated level until $24 \mathrm{~h}$ after the application (Figure 1).

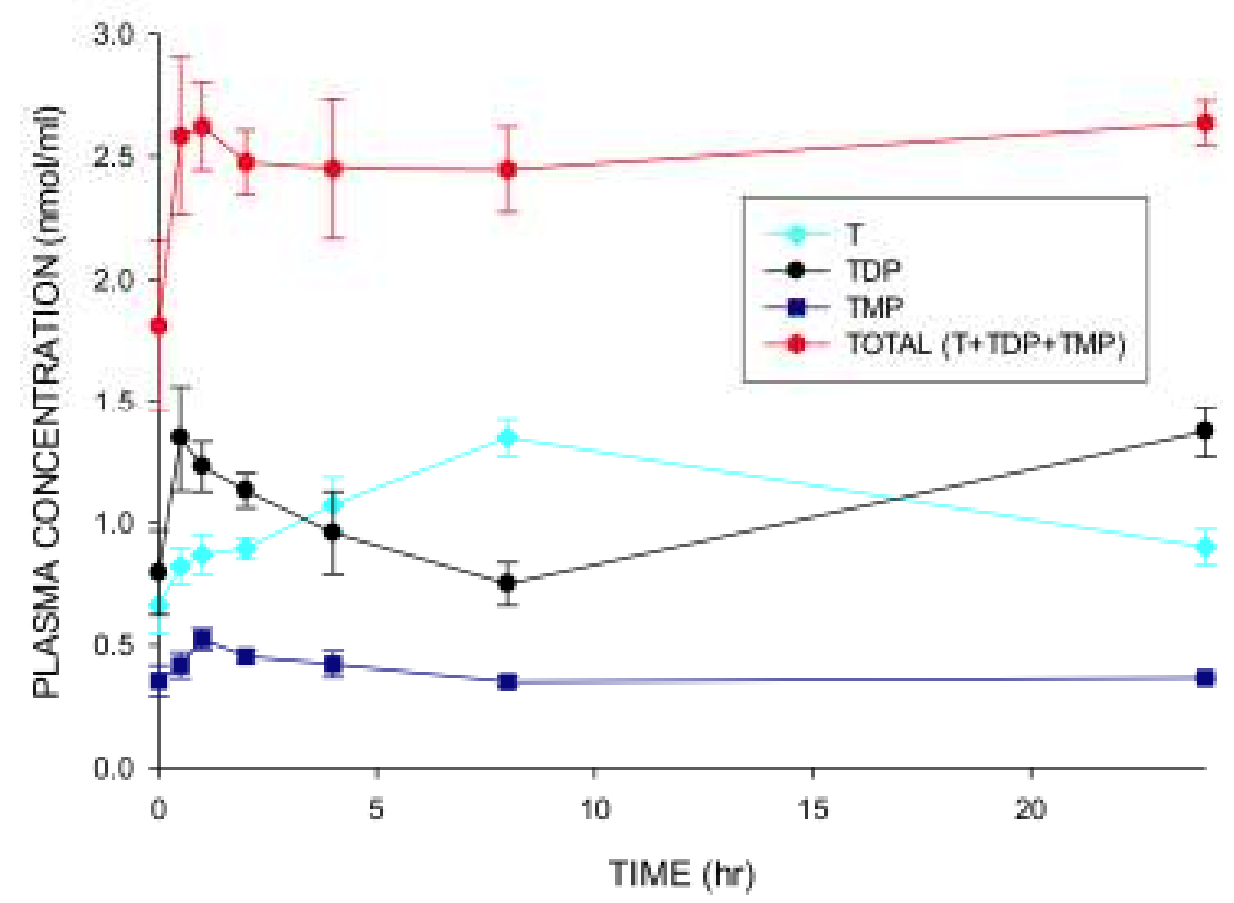

Figure 1. Plasma concentration of cellular metabolites after topical application of $15 \mathrm{mg}$ BC-DN-01 (solubilized). The pharmacokinetic profile of plasma concentrations of thiamine $(T)$, thiamine diphosphate (TDP) and thiamine monophosphate (TMP) were analyzed following the single application $15 \mathrm{mg}$ of topical BC-DN-01. The data shows a rapid penetration through the skin into the plasma for all three thiamine derivatives with a peak for the cumulative group at 1 hour, however, holding an approximate $50 \%$ increase over normal level up to 24 hours. $N=5$ for plasma data.

The application of $0.5 \mathrm{~g}$ of $5 \%$ microcrystalline benfotiamine topical formulation resulted in an appreciable enhancement of thiamine and its phosphorylated derivatives in the blood. Again, a sharp rise was observed in the blood concentration of each of the thiamine derivatives within 30 minutes of the drug application (Figure 2). This enhancement continued to further increase until one hour, followed by a sharp decline in the blood concentration of the individual derivatives and the total remained at an elevated level until $24 \mathrm{hrs}$ after the application. Interestingly, while the microcrystalline formulation contained almost twice as high concentration of the active pharmacological ingredient than the solubilized benfotiamine formulation, the 24 hours steady state concentrations in the blood resembled to those values that were observed with the solubilized formulation containing a lower (3\%) benfotiamine concentration. This is an indication that in case of each applied formulation the benfotiamine level was at saturating concentration. Moreover, the more pronounced rise at one hour and the drastic drop thereafter in the concentration of thiamine derivatives is consistent with a robust overload (Figure 2). 


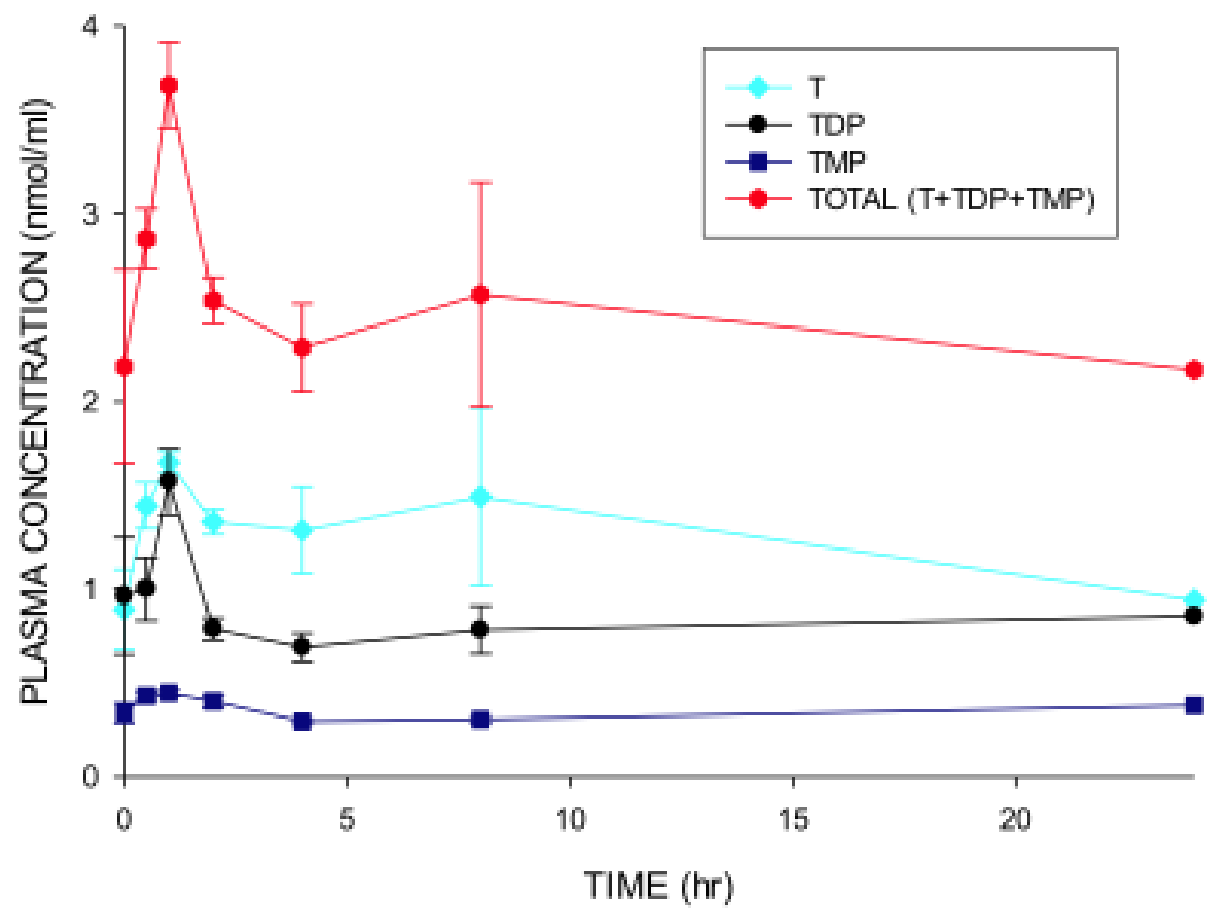

Figure 2. Plasma concentration of cellular metabolites after topical application of $25 \mathrm{mg}$ BC-DN-01 (suspension). The pharmacokinetic profile of plasma concentrations of thiamine (T), thiamine diphosphate (TDP) and thiamine monophosphate (TMP) were analyzed following the single application $25 \mathrm{mg}$ of topical suspended BC-DN-01. The data shows a rapid penetration through the skin into the plasma for all three thiamine derivatives with a peak for the cumulative group at 1 hour with an approximate $70 \%$ increase in the group, however, dropping off to a more normal level by 4 hours. $N=5$ for plasma data at $0.5,1,2,4$ and 8 hours and $N=1$ at $t=24$ hours time point.

The measurement of benfotiamine, S-benzoyl-benfotiamine, thiamine and thiamine related compounds in skin tissues attested that there was no obvious change of TDP and TMP levels compared to controls over the 24 hour period when treated with solubilized benfotiamine cream (Figure 3A). The level of benfotiamine appeared low, however, there was a drastic rise in S-benzoyl thiamine and thiamine levels. As shown in Figure 3A, BFT and S-benzoyl thiamine skin level (stratum corneum removed) was $1.64 \mathrm{nmol} / \mathrm{g}$ and $1,492.33 \mathrm{nmol} / \mathrm{g}$ respectively. Concomitant with these changes, the thiamine level increased from $0.32 \mathrm{nmol} / \mathrm{g}$ to $809.25 \mathrm{nmol} / \mathrm{g}$, resulting in a 2,500-fold enhancement in treated animals.

The results of the accumulation of thiamine and thiamine derivatives in the skin tissue located under the application site after $24 \mathrm{~h}$ treatment with the $5 \%$ microcrystalline formulation are summarized in Figure 3B. Similarly to the treatment with solubilized $3 \%$ benfotiamine formulation, we observed no obvious change of TDP and TMP levels compared to controls over the 24 hour period. The level of benfotiamine appeared low, however, there was a drastic rise in S-benzoyl thiamine and thiamine levels. Concomitantly, the thiamine level increased from $0.32 \mathrm{nmol} / \mathrm{g}$ to $2,538.29 \mathrm{nmol} / \mathrm{g}$ at $t=24$ hours that is a $7,880-$ fold increase in treated animals.

We could not determine the significance of the increase in skin tissue thiamine level after $24 \mathrm{hrs}$ with treatment of $3 \%$ solubilized benfotiamine formulation due to the limited number of animal subjects involved in this experiment $(N=2)$, however, the treatment with the $5 \%$ microcrystalline benfotiamine cream formulation resulted in more robust enhancement in skin tissue thiamine level and this value appeared significant when compared to non-treated control ( $p=0.03$ ) (Figure $3 C$ ). 

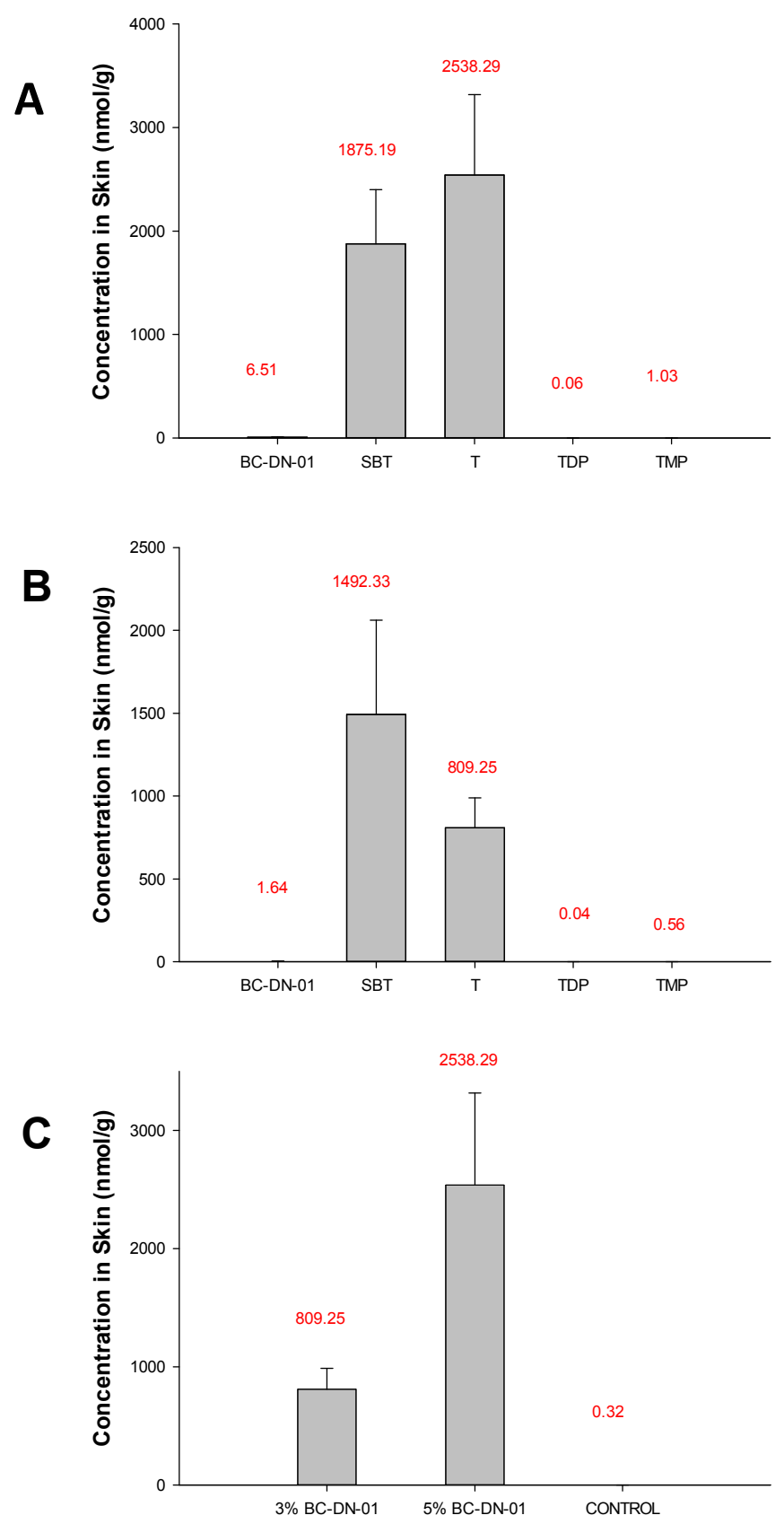

Figure 3. A; Concentration of BC-DN-01 and metabolites in skin tissue $24 \mathrm{~h}$ after $15 \mathrm{mg}$ topical application of BC-DN-01 (solubilized). Analysis of the content of BC-DN-01 in skin tissue following a single application of $15 \mathrm{mg}$ of solubilized $\mathrm{BC}-\mathrm{DN}-01$ at $\mathrm{t}=0$ for the presence of $\mathrm{BC}-\mathrm{DN}-01$, its dephosphorylated intermediate metabolite (SBT), and thiamine (T), thiamine diphosphate (TDP) and thiamine monophosphate (TMP). In addition, control levels of thiamine from untreated skin were analyzed and graphed. $N=3$ for control, BC-DN-01, TDP and TMP in skin tissue samples. $N=2$ for determination of SBT and T in skin tissue samples. B; Concentration of BC-DN-01 and metabolites in skin tissue $24 \mathrm{~h}$ after $25 \mathrm{mg}$ topical application of BC-DN-01 (suspension). Analysis of the content of BC-DN01 in skin tissue following a single application of $25 \mathrm{mg}$ of suspended form of BC-DN-01 at $t=0$ for the presence of BC-DN-01, its dephosphorylated intermediate metabolite (SBT), and the thiamine (T), thiamine diphosphate (TDP) and thiamine monophosphate (TMP). In addition, control levels of thiamine from untreated skin were analyzed and graphed; $N=3$ for skin. C; Thiamine levels in the skin after $24 \mathrm{~h}$ with treatment of $3 \%$ BC-DN-01 and 5\% BC-DN-01. Numbers in red are mean values from independent determinations as indicated in $\mathbf{A}$ and $\mathbf{B}$. 
These pharmacokinetic studies demonstrated that transdermally-delivered benfotiamine is capable of serving as a prodrug for blood and intradermal thiamine production. By making use of alternative drug forms of the benfotiamine as well as modifying the formulation cofactors and solvents we were able to achieve a significant bioavailability in the target tissue of the skin tissue while also protecting the integrity of the molecule for stability purposes. Our experimental data from these pharmacokinetic studies with topical benfotiamine formulation has demonstrated a significant, $\sim 8000$-fold, increase in the level of thiamine chemical species in the skin tissue of animals receiving a single $25 \mathrm{mg}$ dose of topical benfotiamine at the 24 hour time point following the application.

The administration of benfotiamine as a topical prodrug offers several advantages over an oral delivery. Firstly, benfotiamine contains a unique open-ringed structure giving the molecule a significantly higher bioavailability index compared to thiamine [71-73]. Thus, the first pass liver metabolism as well as metabolic conversions of the drug crossing the intestinal wall will be avoided with a topical administration. Secondly, the oral delivery of benfotiamine has been shown to significantly accumulate in the erythrocytes [74] and then in the liver as opposed to being delivered in significant doses to the peripheral nerves in the skin of the legs and hands. Topical delivery of benfotiamine will concentrate the drug in the target tissues immediately without dilution. As a result, the impact on the damaged cells and tissues should respond better than the oral applications.

In contrast to using thiamine as the drug to treat diabetic peripheral neuropathy, benfotiamine is a chemical analog of thiamine that is considerably more bioavailable at the systemic as well as the cellular level than thiamine. Therefore, if administered to patients with diabetic neuropathy, topical benfotiamine should have a favorable efficacy profile through the introduction of greater quantities of thiamine into the cell. Thiamine cellular absorption derived from orally administered benfotiamine is about five times greater than those levels obtained from conventional thiamine supplements [19,71-73]. This differential bioavailability is even greater in the brain and muscle tissues that yield five- to twenty-five-fold more thiamine [22] after a benfotiamine application compared to equivalent doses of thiamine.

For benfotiamine given transdermally, a similar cascade of biochemistry occurs with the dephosphorylation of the native benfotiamine catalyzed by phosphatase enzymes positioned on the outside of epidermal cells producing S-benzoylthiamine. Once in this form, the S-benzoylthiamine prodrug follows the same passive transport across the membrane of the cells of the epidermis and dermis including those of the Schwann cells and neurons, delivering a high dose of the prodrug and subsequently the thiamine to those cells. The thiamine diphosphate produced from the elevated thiamine activates the transketolase and the pentose phosphate pathway, altering the glucose metabolism to reduce the formation of AGEs. Reduction of AGEs in the Schwann and neuronal cells reduces the expression of neuropathy symptoms and also addresses the base etiology of the disease state.

\section{Conclusions}

Conclusions from the proof of concept study in guinea pigs is primarily that after single topical application of either a solution form of benfotiamine $(15 \mathrm{mg}$ ) or a microcrystalline suspension form (25 $\mathrm{mg}$ ) we found considerable increases of the dephosphorylated benfotiamine (S-benzoylthiamine) in the skin tissue as well as significant increases in the thiamine and thiamine phosphate pools compared to control animals. The presence of a $~ 8000 x$ increase in thiamine and increase in its phosphorylated derivatives in the epidermis and dermis tissue of the test animals gives a strong indication that the topical treatment with benfotiamine works very well for the desired outcome of producing an intracellular increase of the activating cofactor pool for transketolase. Subsequently, it is reasonable to conclude that this metabolite 
level increase, including TDP, as a function of cellular compartmentalization of metabolites and pools of the thiamine derivatives, will well serve the diabetic neuropathic disease condition by activating the transketolase and activating the pentose phosphate pathway as an alternative mechanism to metabolize glucose into harmless end-products as opposed to the continued production of advanced glycation endproducts.

Acknowledgements: This work was supported by funds from BioChemics, Inc.

\section{References}

[1] M. Brownlee, Nature 414 (2001) 813-820.

[2] H.P. Hammes, X. Du, D. Edelstein, T. Taguchi, T. Matsumura, Q, Ju, J. Lin, A. Bierhaus, P. Nawroth,D. Hannak, M. Neumaier, R. Bergfeld, I. Giardino, M. Brownlee, Nature Med. 9 (2003) 294-299.

[3] K.A. Head, Altern. Med. Rev. 11 (2006) 294-329.

[4] T. Varkonyi, P. Kempler, Diabetes Obes. Metab. 10 (2008) 99-108.

[5] A. Bierhaus, T. Fleming, S. Stoyano, A. Leffler, A. Babes, C. Neacsu, S.K. Sauer, M. Eberhard, M. Schnölze, F. Lasischka, W.L. Neuhuber, T.I. Kichko, I. Konrade, R. Elvert, W. Mier, V. Pirags, I.K. Lukić, M. Morcos, T. Dehmer, N. Rabbani, P.J. Thornalley, D. Edelstein, C. Nau, J. Forbes, P.M. Humpert, M. Schwaninger, D. Ziegler, D.M. Stern, M.E. Cooper, U. Haberkorn, M. Brownlee, P.W. Reeh, P.P. Nawroth, Nature Med. 18 (2012) 926-933.

[6] The Diabetes Control and Complications Trial Research Group. New Engl. J. Med. 329 (1993) 977986.

[7] The Effect of Intensive Diabetes Therapy on the Development and Progression of Neuropathy. Ann. Int. Med. 122 (1995) 561-568.

[8] M.C. Wong, J.W. Chung, T.K. Wong, BMJ (2007) 335:387.

[9] R.H. Dworkin, D.C. Turk, K.W. Wyrwich, D. Beaton, C.S. Cleeland, J.T. Farrar, J.A. Haythornthwaite, M.P. Jensen, R.D. Kerns, D.N. Ader, N. Brandenburg, L.B. Burke, D. Cella, J. Chandler, P. Cowan, R. Dimitrova, R. Dionne, S. Hertz, A.R. Jadad, N.P. Katz, H. Kehlet, L.D. Kramer, D.C. Manning, C. McCormick, M.P. McDermott, H.J. McQuay, S. Patel, L. Porter, S. Quessy, B.A. Rappaport, C. Rauschkolb, D.A. Revicki, M. Rothman, K.E. Schmader, B.R. Stacey, J.W. Stauffer, T. von Stein, R.E. White, J. Witter, S. Zavisi, Pain 9 (2008) 105-121.

[10] R.A. Moore, S. Straube, P.J. Wiffen, S. Derry, H.J. McQuay, The Cochrane Database of Systematic Reviews (2009) Cd007076.

[11] S. Quilici, J. Chancellor, M. Lothgren, D. Simon, G. Said, T.K. Le, A. Garcia-Cebrian, B. Monz, BMC Neurology 9 (2009) 6.

[12] S. Derry, A. Sven-Rice, P. Cole, T. Tan, R.A. Moore, The Cochrane Database of Systematic Reviews 2 (2013) Cd007393.

[13] G.L. Page, D. Laight, M.H. Cummings, Int. J. Clin. Pract. 65 (2011) 684-690.

[14] N. Rabbani, P.J. Thornalley, Diabetes Obes. Metab. 13 (2011) 577-583.

[15] M. Gangolf, J. Czerniecki, M. Radermecker, O. Detry, M. Nisolle, C. Jouan, D. Martin, F. Chantraine, B. Lakaye, P. Wins, T. Grisar, L. Bettendorff, PLoS One 5 (2010) e13616.

[16] P.J. Thornalley, R. Babaei-Jadidi, H. Al Ali, N. Rabbani, A. Antonysunil, J. Larkin, A. Ahmed, G. Rayman, C.W. Bodmer, Diabetologia 50 (2007) 2164-2170.

[17] J. R. Larkin, F. Zhang, L. Godfrey, G. Molostvov, D. Zehnder, N. Rabbani, P. J. Thornalley, PLoS One 7 (2012) e53175.

[18] R. Babaei-Jadidi, N. Karachalias, N. Ahmed, S. Battah, P.J. Thornalley, Diabetes 52 (2003) 2110-2120.

[19] R. Masson, C. Quincy, P. Girard, R. Later, B. Bochu, M.F. Cotte, Lyon Med. 216 (1966) 685-704.

[20] R. Hilbig H. Rahmann, Arzneimittelforschung 48 (1998) 461-468. 
[21] H. Stracke, H.P. Hammes, D. Werkmann, K. Mavrakis, I. Bitsch, M. Netzel, J. Geyer, W. Köpcke, C. Sauerland, R.G. Bretzel, K.F. Federlin, Exp. Clin. Endocrinol. Diabetes 109 (2001) 330-336.

[22] M. L. Volvert, S. Seyen, M. Piette, B. Evrard, M. Gangolf, J. C. Plumier, L. Bettendorf, BMC Pharmacol. 8 (2008) 10.

[23] E. Beltramo, E. Berrone, S. Tarallo, M. Porta, Acta Diabetol. 45 (2008), 131-141.

[24] H. Woelk, S. Lehrl, R. Bitsch, W. Kopcke, Alcohol 33 (1998) 631-638.

[25] E.I. Anisimova, A.B. Danilov, Zh. Nevrol. Psikhiatr. Im. S. S Korsakova 101 (2001) 32-36.

[26] E. Haupt, H. Ledermann, W. Kopcke, Int. J. Clin. Pharmacol. Ther. 43 (2005) 71-77.

[27] G. Winkler, B. Pal, E. Nagybeganyi, I Ory, M. Porochnavec, P. Kempler, Arzneimittelforschung 49 (1999) 220-224.

[28] H. Stracke, W. Gauss, U. Achenbach, K. Federlin, R.G. Bretzel, Exp. Clin. Endocrinol. Diabetes 116 (2008) 600-605.

[29] X. Du, D. Edelstein, M. Brownlee, Diabetologia 51 (2008) 1930-1932.

[30] C.D. Ang, M.J. Alviar, A.L. Dans, G.G. Bautista-Velez, V.V. Villaruz-Sulit, J.J. Tan, H.U. Co, M.R. Bautista, Cochrane Database Systematic Reviews 16 (2008) Cd004573.

[31] N. Karachalias, R. Babaei-Jadidi, N. Ahmed, P.J. Thornalley, Biochem. Soc. Trans. 31 (2003) 14231425.

[32] R. Babaei-Jadidi, N. Karachalias, C. Kupich, N. Ahmed, P.J. Thornalley, Diabetologia 47 (2004) 22352246.

[33] N. Karachalias, R. Babaei-Jadidi, C. Kupich, N. Ahmed, P.J. Thornalley, Ann. N. Y. Acad. Sci. 1043 (2005) 777-783.

[34] N. Karachalias, R. Babaei-Jadidi, N. Rabbani, P.J. Thornalley, Diabetologia 53 (2010) 1506-1516.

[35] A.F. Ceylan-Isik, S. Wu, Q. Li, S. Y. Li, J. Ren, J. Appl. Physiol. 100 (2006) 150-156.

[36] Y. Kohda, H. Shirakawa, K. Yamane, K. Otsuka, T. Kono, F. Terasaki, T. Tanaka, J. Toxicol. Sci. 33 (2008) 459-472.

[37] S. Wu, J. Ren, Neurosci. Lett. 394 (2006) 158-162.

[38] S. Gadau, C. Emanueli, S. Van Linthout, G. Graiani, M. Todaro, M. Meloni, I. Campesi, G. Invernici, F. Spillmann, K. Ward, P. Madeddu, Diabetologia 49 (2006) 405-420.

[39] G.M. Sanchez-Ramirez, N.L. Caram-Salas, H.I. Rocha-Gonzalez, G.C. Vidal-Cantu, R. MedinaSantillan, G. Reyes-Garcia, Eur. J. Pharmacol. 530 (2006) 48-53.

[40] R.G. Katare, A. Caporali, A. Oikawa, M. Meloni, C. Emanueli, P. Madeddu, Circ. Heart Fail. 3 (2010) 294-305.

[41] R. Katare, A. Caporali, C. Emanueli, P. Madeddu, J. Mol. Cell Cardiol. 49 (2010) 625-638.

[42] Y. Kohda, M. Umeki, T. Kono, F. Terasaki, H. Matsumura, T. Tanaka, J. Pharmacol. Sci. 113 (2010) 343-352.

[43] R. Katare, A. Oikawa, D. Cesselli, A.P. Beltrami, E. Avolio, D. Muthukrishnan, P.E. Munasinghe, G. Angelini, C. Emanueli, P. Madeddu, Cardiovasc. Res. 97 (2013) 55-65.

[44] H. Stracke, A. Lindemann, K. Federlin, Exp. Clin. Endocrinol. Diabetes 104 (1996) 311-316.

[45] E. Haupt, H. Ledermann, W. Köpcke, Int. J. Clin. Pharmacol. Ther. 43 (2005) 71-77.

[46] S. Arora, A. Lidor, C.J. Abularrage, J.M. Weiswasser, E. Nylen, D. Kellicut, A.N. Sidawy, Ann. Vasc. Surg. 20 (2006) 653-658.

[47] X. Du, D. Edelstein, M. Brownlee, Diabetologia 51 (2008) 1930-1932.

[48] N. Schupp, E.M. Dette, U. Schmid, U. Bahner, M. Winkler, A. Heidland, H. Stopper, Naunyn Schmiedebergs Arch. Pharmacol. 378 (2008) 283-291.

[49] S. Riaz, V. Skinner, S.K. Srai, J. Pharm. Biomed. Anal. 54 (2011) 817-825.

[50] N. Rabbani, S.S. Alam, S. Riaz, J.R. Larkin, M.W. Akhtar, T. Shafi, P.J. Thornalley, Diabetologia 52 (2009) 208-212. 
[51] A. Alkhalaf, A. Klooster, W. van Oeveren, U. Achenbach, N. Kleefstra, R.J. Slingerland, G.S. Mijnhout, H.J. Bilo, R.O. Gans, G.J. Navis, S.J. Bakker, Diabetes Care, 33 (2010) 1598-1601.

[52] M. González-Ortiz, E. Martínez-Abundis, J.A. Robles-Cervantes, V. Ramírez-Ramírez, M.G. Ramos-Zavala, Eur. J. Nutr. 50 (2011) 145-149.

[53] A. Alkhalaf, N. Kleefstra, K.H. Groenier, H.J. Bilo, R.O. Gans, P. Heeringa, J.L. Scheijen, C.G. Schalkwijk, G.J. Navis, S.J. Bakker, PLoS One 7 (2012) e40427.

[54] D.A. Fraser, L.M. Diep, I.A. Hovden, K.B. Nilsen, K.A. Sveen, I. Seljeflot, K.F. Hanssen, Diabetes Care 35 (2012) 1095-1097.

[55] F.C. Polizzi, G. Andican, E. Çetin, S. Civelek, V. Yumuk, G. Burçak, Exp. Clin. Endocrinol. Diabetes 120 (2012) 329-334.

[56] A. Stirban, A. Pop, A. Fischer, S. Heckermann, D. Tschoepe, Diabetes Technol. Ther. 15 (2013) 733737.

[57] A. Stirban, A. Pop, D. Tschoepe, Diabet. Med. 30 (2013) 1204-1208.

[58] E. Berrone, E. Beltramo, C. Solimine, A.U. Ape, M. Porta, J. Biol. Chem. 281 (2006) 9307-9313.

[59] V. Marchetti, R. Menghini, S. Rizza, A. Vivanti, T. Feccia, D. Lauro, A. Fumikazu, R. Lauro, M. Federici, Diabetes 55 (2006) 2231-2237.

[60] F. Pomero, A. Min Molinar, M. La Selva, A Allione, G.M. Molinatti, M. Porta, Acta Diabetol. 38 (2001) 135-138.

[61] E. Beltramo, E. Berrone, S. Buttiglieri, M. Porta, Diabetes Metab. Res. Rev. 20 (2004) 330-336.

[62] S.H. Oh R.P. Witek, S.H. Bae, H.A. Darwiche, Y. Jung, L. Pi, A. Brown, B.E. Petersen, Stem Cells Dev. 18 (2009) 37-46.

[63] T. Hanawa, A. Watanabe, T. Tsuchiya, R. Ilkoma, M. Hidaka, M. Sugihara, Chem. Pharm. Bull. (Tokyo) 43 (1995) 872-876.

[64] S. Simeonov, M. Pavlova, M. Mitkov, L. Mincheva, D. Troev, Folia Med. (Plovdiv) 39 (1997) 5-10.

[65] S.G. Carter, Z. Zhu, G. Varadi, A. Veves, J.E. Riviere, J. Pharmaceut. Sci. 102 (2013) 4072-4078.

[66] C. Herve, P. Beyne, E. Delacoux, J. Chromatogr. B, 653 (1994) 217-220.

[67] M. Ziems, M. Netzel, S. Peter, I. Bitsch, Vitamine und Zusatzstoffe in der Ernahrung von Mensch und Tier, 5. Symposium Jena (1995) 320-323

[68] P.L.M. Lynch, E.R. Trimble, I.S. Young, J. Chromatogr. B, 701 (1997) 120-123.

[69] D. Talwar, H. Davidson, J. Cooney, D.St. JO'Reilly, Clinical Chemistry 46 (2000) 704-710.

[70] B.A.J. Van Landeghem, J. Puts, H.A. Claessens, J. Chromatogr. B, 822 (2005) 316-321.

[71] D. Loew, Int. J. Clin. Pharmacol. Ther. 34 (1996) 47-50.

[72] A. Greb, R. Bitsch, Int. J. Clin. Pharmacol. 36 (1998) 216-221.

[73] T. Frank, R. Bitsch, J Maiwald, G. Stein, Eur. J. Clin. Pharmacol. 56 (2000) 251-257.

[74] R. Bitsch, M. Wolf, J. Moller, L. Heuzeroth, D. Gruneklee, Ann. Nutr. Metab. 35 (1991) 292-296.

C 2014 by the authors; licensee IAPC, Zagreb, Croatia. This article is an open-access article distributed under the terms and conditions of the Creative Commons Attribution license (http://creativecommons.org/licenses/by/3.0/) (cc)) EY 